\title{
U-shaped masking functions under backward masking by pattern mask
}

\author{
DEAN G. PURCELL \\ Oakland University, Rochester, Michigan 48063
}

ALAN L. STEWART

New York University, New York, New York 10003

\author{
JERRY DAVIS, JAMES HUNTERMARK, STEVE ROBBINS, PAUL ROWLAND, and KAREN SALLEY \\ University of Arkansas, Fayetteville, Arkansas 72701
}

\begin{abstract}
Tests were made of the influence of target luminance, target and mask luminance, retinal position, and observer's task on visual backward masking by a patterned mask. U-shaped masking functions were obtained when the performance of observers was equated through manipulation of either the experimental task or the retinal position of the target.
\end{abstract}

Visual backward masking by a patterned mask is generally thought to yield only monotonic masking functions as long as the masking pattern falls across the retinal area stimulated by the target stimulus (Kahneman, 1968). By comparison, in metacontrast, where the masking pattern does not overlap the stimulus pattern, U-shaped masking functions are sometimes found. Recently, backward masking by a patterned stimulus has also been found to yield U-shaped masking functions, provided that the target stimulus has more energy than the masking stimulus (Turvey, 1973; Purcell \& Stewart, 1970). The present study was designed to outline some additional conditions necessary for U-shaped masking functions to be obtained with a patterned mask consisting of a white field containing black, overlapping line segments. The effects of changing target luminance relative to the mask, the absolute values of target and mask luminance, retinal location of the target stimulus, and observer's task were each studied. In the case of the observer's task, target recognition was compared with target detection.

\section{GENERAL METHOD}

\section{Observers}

Four trained observers served in the following experiments. Two observers had had about $10 \mathrm{~h}$ previous experience under conditions of visual masking. The other two observers had had over $100 \mathrm{~h}$ experience under conditions of masking.

\section{Stimuli and Apparatus}

One target stimulus set consisted of black on white capital letters $\mathrm{A}$ and $\mathrm{T}$. The A subtended .53 by .40 deg with a strip width of $.06 \mathrm{deg}$. These stimuli were used in all forced-choice recognition tasks. The second stimulus set consisted of two black

Research was partially supported by a grant from the Social and Rehabilitation Service to the second author. Requests for reprints should be sent to D. G. Purcell, Department of Psychology, Oakland University, Rochester, Michigan 48063. on white rings. One ring was continuous while the second had a break at its top, so that it formed an upright $\mathrm{C}$-shaped ring. In the detection task, the broken ring was the target. The size of this break was adjusted for each observer so as to give between $70 \%$ and $90 \%$ correct detection when the target and mask were exposed simultaneously (Procedure D, following). The strip width of these figures was $.06 \mathrm{deg}$. The outer diameter of either ring subtended $.53 \mathrm{deg}$. All target stimuli were presented $.56 \mathrm{deg}$ to the right of the fixation point.

The mask consisted of overlapping columns and rows of the capital letters $\mathrm{N}$ and $\mathrm{O}$. The individual letters comprising the mask were the same size as the target stimuli. The mask covered the mask field. The target and mask fields were square, subtending $3 \mathrm{deg}$ on each side. The duration of both target and mask was constant at 20 msec. The dark fixation field was defined by four 1-min red dots arranged in a diamond pattern, with a fixation dot in the center. Additional red fixation points were located 1.12 and $2.24 \mathrm{deg}$ to the left of the center of the fixation field on the central horizontal plane.

In all experimental procedures, the independent variable was the time from target onset to mask onset. Five different values of the stimulus onset asynchrony (SOA) were used-0, -10 , $-20,-30$, and $-60 \mathrm{msec}$. All data were collected under each procedure before proceeding to the next experimental situation. Within an experimental procedure, data at each SOA were collected in random blocks of ten trials each. A total of 50 trials was run at each SOA. Each observer served under each experimental procedure. Observers were dark adapted for $10 \mathrm{~min}$ before data collection. A 10 -sec intertrial interval was maintained. The preexposure, postexposure, and interstimulus intervals were dark. All observations were monoptic with the right eye. An Iconix four-channel tachistoscope was used to present the stimuli. Observers initiated each trial at a ready signal from the experimenter.

\section{FIVE VISUAL MASKING CONDITIONS}

\section{Procedure A}

Method. The target was a single letter, either A or T, presented in random order. Observers made a forced-choice decision as to which letter was presented. The luminance of the white field surrounding the black letter was $65 \mathrm{~cd} / \mathrm{m}^{2}$. The luminance of the black letter was $6.4 \mathrm{~cd} / \mathrm{m}^{2}$. The luminance of the white portions of the mask was $50 \mathrm{~cd} / \mathrm{m}^{2}$. The luminance of 
Table 1

Mean Percentage Correct Target Report for Values of Stimulus Onset Asynchrony (SOA)

\begin{tabular}{|c|c|c|c|c|c|c|}
\hline \multirow{2}{*}{$\begin{array}{l}\stackrel{0}{0} \\
\text { D } \\
\text { D. }\end{array}$} & \multicolumn{6}{|c|}{ Stimulus Onset Asynchrony (in Msec) } \\
\hline & 0 & -10 & -20 & -30 & -60 & No Mask \\
\hline A & 98.50 & 99.00 & 95.50 & 87.00 & 93.50 & \\
\hline $\mathrm{B}$ & 98.00 & 92.50 & 84.50 & 87.50 & 93.00 & \\
\hline C & 79.50 & 84.50 & 79.50 & 77.50 & 80.00 & 80.50 \\
\hline $\mathrm{D}$ & 80.25 & 69.75 & 64.50 & 62.00 & 65.50 & \\
\hline $\mathrm{E}$ & 55.00 & 53.50 & 60.00 & 66.00 & 79.00 & \\
\hline
\end{tabular}

the black portions of the mask was $4.8 \mathrm{~cd} / \mathrm{m}^{2}$. Fixation was at the center of the fixation field.

Results. The results for Procedure A, as well as for all other procedures, are given in Table 1 . There were no statistically significant masking effects in Condition $\mathrm{A}$. Two observers made no errors in target recognition. Performance of the other two observers was worst at the intermediate values of SOA.

\section{Procedure B}

Method. All conditions were the same as in Procedure A except that the fixation position was selected individually for each observer. In each case, with SOA held constant at -20 msec, the fixation point was adjusted until the observer's performance fell to between $70 \%$ and $90 \%$ correct recognition. Accordingly, two observers continued to fixate the center of the fixation field. The third observer used a fixation point $1.68 \mathrm{deg}$ from the point at which the target was presented. The fourth observer used a fixation point $2.80 \mathrm{deg}$ from the point at which the target was presented. Procedure B was the only situation in which the point of fixation was varied.

Results. There was a statistically significant masking effect, with target recognition decreasing as SOA increased from zero to $-20 \mathrm{msec}[\mathrm{F}(2 / 6)=35.29, \mathrm{p}<.001]$.

\section{Procedure $\mathbf{C}$}

Method. Procedure $C$ was identical to Procedure A except that neutral density filters were added to both target and mask fields. Luminance levels were varied by means of these filters so that the performance of each observer at $-20 \mathrm{msec}$ SOA was fixed to a criterion of $70 \%$ to $90 \%$ correct. Accordingly, the target and mask luminance levels were reduced by $2.5,2.3,2.2$, or $2.1 \log$ units, depending upon the individual observer. A control condition was added in order to test the observer's ability to identify the target letters when no mask followed their onset. The target letters were presented without a mask for a total of 50 trials. The trials without mask were interspersed, in blocks of 10 trials, among the blocks of masking trials.

Results. Observer performance showed no marked change throughout the range of SOA values tested, nor was there a difference between mask and no-mask presentations. Thus, there was no indication of masking with this procedure.

\section{Procedure D}

Method. Procedure D was identical to Procedure A except for the target stimuli. The targets consisted of either a ring, or a ring with a break at its top. The size of the break in the ring was selected for each individual observer so as to yield a score of between $70 \%$ and $90 \%$ correct target report at $-20 \mathrm{msec}$ SOA. For two observers the width of the break was $.132 \mathrm{deg}$; for the third observer it was $.066 \mathrm{deg}$, and for the fourth observer it was $.033 \mathrm{deg}$.

Results. Performance decreased systematically over the first four SOA values. Statistical analysis gave $[F(2 / 6)=6.63$, $\mathrm{p}<.05]$. Thus, a simple detection task under these luminance and duration conditions produced a U-shaped masking function.

\section{Procedure E}

Method. Procedure E differed from Procedure D only in that the target was attenuated by .3 log units.

Results. Under these conditions, observer performance improved steadily as SOA increased, yielding a monotonic masking function $[F(4 / 12)=4.06, p<.05]$. A comparison of Procedures D and E at -30 and $-60 \mathrm{msec}$ SOA demonstrates that target detection was better for the low energy conditions of Procedure E. Statistical analysis gave $[F(1 / 3)=12.62, p<.05]$.

\section{GENERAL DISCUSSION}

Both U-shaped and monotone masking functions can be obtained with either recognition or identification tasks; by the same token, the fact that a masking stimulus is a complex pattern does not, by itself, seem to determine the form of the masking function. Before statistically reliable $U$-shaped functions emerge, however, certain conditions must be met. For one, conditions must be manipulated so as to produce a measurable variation in each observer's performance throughout all tested values of SOA. And further, performance at very short values of SOA, when target and mask stimuli overlap in time, must be tested. Because of their size, target letters used in Procedure A, for example, did not induce a measurable change in the performance of two observers, and thus resulted in a failure to produce a statistically reliable decrement in performance over the first few SOA values. Changing the point of fixation for these two otservers, however, as in Procedure B, increased the difficulty of discriminating the target. U-shaped masking functions were then readily apparent for all observers. Similarly, changing the targets to ones harder to discriminate, such as the ring targets of Procedure D, produced masking conditions which were otherwise identical to those of Procedure A.

Although equating task difficulty among observers is a necessary condition for ensuring that $U$-shaped functions will be reliably documented, this is certainly not a sufficient condition for their occurrence. Indeed, while a number of arbitrary manipulations of masking parameters can serve to equate observer performance, some of these manipulations also serve to eliminate nonmonotone masking functions (see the discussion in Stewart \& Purcell, 1974). Thus, the primary problem in demonstrating U-shaped masking functions rests with finding manipulations which will allow the experimenter to equate task difficulty for each observer while at the same time maintaining conditions sufficient for producing nonmonotone masking functions. It is not clear, for example, why reducing the luminance level of both target and mask in Procedure $C$ resulted in reduced performance, but gave no evidence of masking. It is possible that at low levels of target and mask energy, the mask must have more energy than the target to have an effect. By contrast, the available data suggest that the target must have greater energy than the mask if U-shaped functions are to be found with a patterned mask paradigm (Turvey, 1973; Purcell \& Stewart, 1970). This, by itself, does not seem to be a sufficient condition; however, the results of Procedure $C$ suggest that the absolute level of target and mask energies may also be a factor in producing nonmonotonic functions. Nor is it clear that the effect of manipulating retinal position, as in Procedure $B$, is due to changes in visual acuity. Changes in recognition directly due to the manipulation of target size, however, as in Procedure D, support an acuity hypothesis.

The finding that U-shaped masking functions may be obtained with a patterned mask is consistent with two quite different conceptions of visual backward masking (Stewart \& Purcell, 1974; Purcell \& Stewart, 1970; and Turvey, 1973). These findings may also be consistent with models of metacontrast, provided that patterned masks can be considered a more general case of metacontrast (Weisstein, 1968). However, these models 
have yet to be formulated so as to deal specifically with our finding that the outcome of a masking interaction may be determined not only by the target to mask energy ratios, but by the absolute level of target and mask energy, as well.

\section{REFERENCES}

Kahneman, D. Method, findings, and theory in studies of visual masking. Psy chological Bulletin, 1968, 70, 404-423.

Purcell, D. G., \& Stewart, A. L. U-shaped backward masking functions with nonmetacontrast paradigms. Psychonomic Science, $1970,21,361-363$.
Stewart, A. L., \& Purcell, D. G. Visual backward masking by a flash of light: A study of U-shaped detection functions. Journal of Experimental Psy chology, 1974, 103, 553-566.

Turvey, M. T. On peripheral and central processes in vision: In ferences from an information-p rocessing analysis of masking with patterned stimuli. Psy chological Review, 1973, 80, 1-52. Weisstein, N. A Rashevsky-Landahl neural net: Simulation of metacontrast. Psy chological Review, 1968, 75, 494-521.

(Received January 27, 1975.) 